\title{
Developmental Psychologist
}

National Cancer Institute

\section{Source}

National Cancer Institute. Developmental Psychologist. NCI Thesaurus. Code C147462.

A psychologist who specializes in diagnosing and treating emotional and behavioral

problems associated with developmental delay or disability. 